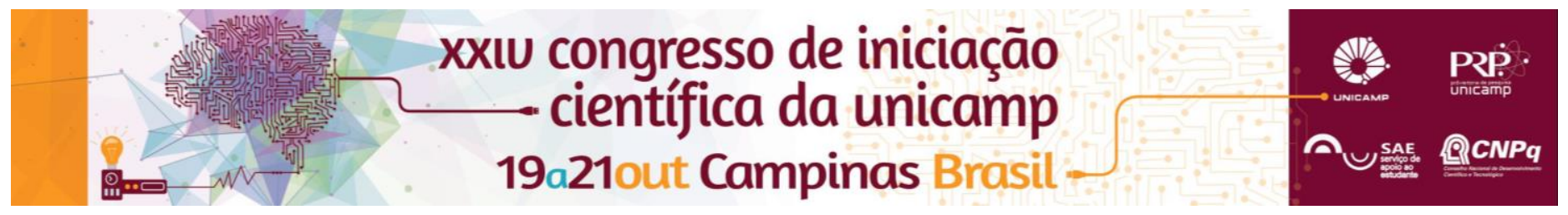

\title{
METODOLOGIA DE OBTENÇÃO DE COORDENADAS DO CONTORNO DA ÁRVORE E DOS PONTOS DE MEDIÇÃO PARA USO EM SOFTWARE DE TOMOGRAFIA ULTRASSÔNICA.
}

\author{
Marcelo Martimiano Junior*, Raquel Gonçalves, Stella S. A. Palma.
}

\begin{abstract}
Resumo
A necessidade de ferramentas tecnológicas para inspecionar árvores e estruturas de madeira de forma mais objetiva, fez com que resultados de pesquisas nesta área fossem rapidamente incorporados pelo setor produtivo. Por essa razão, observa-se que, apesar de já haver tomógrafos industriais em uso, continua existindo muitas pesquisas sendo realizadas na área, mostrando ainda ter muito espaço para o desenvolvimento científico e tecnológico. O grupo de pesquisa em Ensaios Não Destrutivos da Faculdade de Engenharia Agrícola - UNICAMP vem atuando no desenvolvimento de metodologia, de software e de equipamento de tomografia ultrassônica. O objetivo deste projeto de iniciação científica foi a melhoria e a simplificação do cálculo das coordenadas do contorno do fuste de árvores e dos pontos de medição por ultrassom, visando maior automação do processo de uso do software desenvolvido pelo grupo.
\end{abstract}

\section{Palavras-chave}

Tomografia Ultrassônica, gerador de contorno, ensaio não destrutivo.

\section{Introdução}

Muitos avanços foram alcançados nos últimos anos no entendimento das potencialidades e das limitações dos métodos não destrutivos para caracterizar, classificar e inspecionar a madeira. No Laboratório de Ensaios Não Destrutivos (LabEND) da Faculdade de Engenharia Agrícola (FEAGRI) da Universidade Estadual de Campinas (UNICAMP) as pesquisas vêm acompanhando os avanços ocorridos no mundo. No entanto, há muitos desafios a serem vencidos, havendo, portanto, necessidade de dar continuidade às pesquisas nesta área. Um dos desafios deste grupo de pesquisa tem sido o de avançar, de forma gradativa, nas questões que envolvem este tema, não somente na aplicação da técnica, mas sempre contemplando a vertente científica que envolve o entendimento das bases teóricas de seu comportamento bem como a nacionalização de equipamentos. O objetivo desta pesquisa de iniciação científica foi melhorar o processo atualmente utilizado para a obtenção e a organização dos dados relativos às coordenadas do contorno do fuste de árvores e dos pontos de medição da malha de difração, visando maior facilitação, automação e redução de erros no processo de organização e elaboração das planilhas utilizadas no software de geração de imagem de tomografia ultrassônica desenvolvido pelo grupo (ImageWood versão 2.0).

\section{Resultados e Discussão}

Para atingir o objetivo deste trabalho foi desenvolvido um software intitulado Gerador de Contorno Regular (GCR), o qual, a partir da entrada de informações (Figura 1), como diâmetro maior e menor do fuste da árvore, número de pontos de medição e o tempo de propagação da onda ultrassônica de cada medição, gera duas saídas: um arquivo com as coordenadas do contorno da árvore analisada e um arquivo com as coordenadas dos pontos de medição da malha de difração e os tempos médios de propagação da onda de cada medição. Ambos os arquivos (Figura 2) são gerados pelo GCR em formato de planilha (.xIsx), estando prontos para serem utilizados pelo software ImageWood.

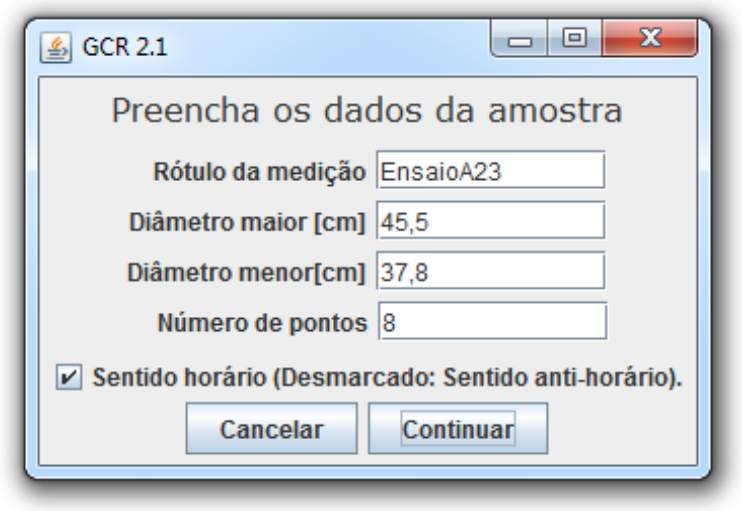

Figura 1. Aplicativo GCR: Entrada dos dados.

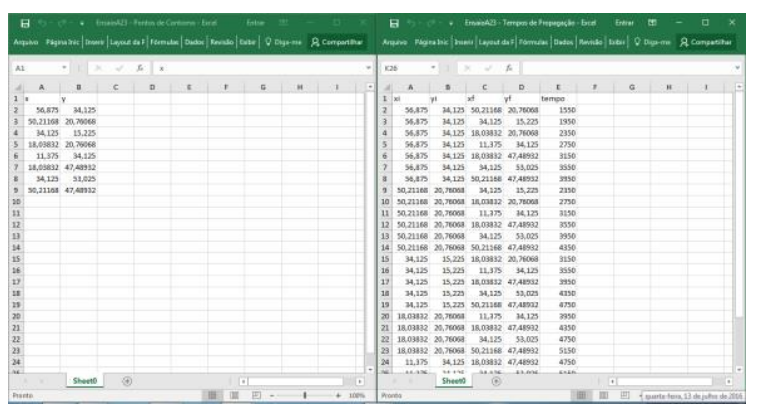

Figura 2. Arquivos de saída do GCR.

\section{Conclusões}

O software desenvolvido automatizou o processo de obtenção do contorno do fuste de árvore e da geração da planilha de coordenadas para inserção do tempo de propagação das ondas de ultrassom, reduzindo a probabilidade de erros desse processo que anteriormente era feito de forma manual.

\section{Agradecimentos}

Agradecemos à FAPESP (Proc. 2015/05692-3) pelo apoio financeiro e ao CNPq e CAPES pelas bolsas de Iniciação Científica e de Mestrado, respectivamente. 